\title{
Paraplegia
}

\section{Effect of Continuous Versus Intermittent Turning on Nursing and Non-nursing Care Time for Acute Spinal Cord Injuries}

\author{
J. M. Bugaresti, ${ }^{1}$ MD, FRCPC, C. H. Tator, ${ }^{2}$ MD, PhD, FRCSC, J. P. Szalai, ${ }^{3}$ \\ PhD \\ ${ }^{1}$ Department of Physical Medicine and Rehabilitation, ${ }^{2}$ Spinal Cord Injury Treatment, \\ Research and Prevention Centre, Toronto Western Hospital, ${ }^{3}$ Department of Biostatistics, \\ Sunnybrook Medical Centre, University of Toronto, Toronto, Ontario, Canada.
}

\section{Summary}

The present study was conducted to determine whether automated, continuous turning beds would reduce the nursing care time for spinal cord injured (SCI) patients by freeing hospital staff from manual turning of patients every 2 hours. Seventeen patients were randomly assigned to continuous or intermittent turning and were observed during the 8 hour shift for 1 to 18 days following injury. Trained observers recorded the time taken for patient contact activities performed by the nursing staff (direct nursing care) and other hospital staff. The mean direct nursing care time per dayshift per patient was $130 \pm 22$ (mean $\pm S D)$ minutes for 9 patients managed with continuous turning and $115 \pm 41$ (mean $\pm S D)$ minutes for 8 patients managed with intermittent turning. The observed difference in care time between the two treatment groups was not significant ( $p>0.05)$. Numerous factors including neurological level, time following injury, and medical complications appeared to affect the direct nursing care time. Although continuous turning did not reduce nursing care time it offered major advantages for the treatment of selected cases of acute SCI.

Some major advantages of continuous turning treatment were observed. Spinal alignment was easier to maintain during continuous turning in patients with injuries of the cervical spine. Continuous turning allowed radiological procedures on the spine, chest and adbomen to be more easily performed without having to alter the patients' position in bed. Therapy and nursing staff indicated that the continuous turning bed facilitated patient positioning for such activities as chest physiotherapy. With continuous turning, one nurse was sufficient to provide care for an individual SCI patient without having to rely on the assistance of other nurses on the ward for patient turning every 2 hours.

Key words: Acute spinal cord injury; Turning beds; Passive motion; Nursing care time.

Patients with acute spinal cord injury (SCI) require intensive and specialised care by a multi-disciplinary team. Their consumption of numerous hospital services

Correspondence to: J. M. Bugaresti, MD, FRCPC, Toronto Western Hospital, 399 Bathurst Street, Toronto, Ontario M5T 2S8, Canada. 
such as occupational therapy, physiotherapy, and, in particular, nursing care exceeds the average for hospitalised patients in acute care settings (Stoddard and Verrier, 1980). Use of continuous turning has been recommended as a method of reducing nursing care time by decreasing the time required for patient positioning and turning (Adelstein and Watson 1983). As nursing salaries are known to comprise 30 to $60 \%$ of hospital operating budgets, this potential saving of staff time is of particular interest (Thompson and Wilson, 1981). The following study was undertaken to establish if nursing care time required for SCI patients treated with automated, continuous turning was less than with the standard method of manual, intermittent turning.

This study was conducted simultaneously with a prospective trial to evaluate the overall effect of continuous turning on the length of hospital stay, and the number of medical complications in patients with acute SCI. The study was conducted on three hospital wards of the Sunnybrook Medical Centre, a major teaching hospital, between June 1984 and March 1985. The three wards included two intensive care units, the Acute Spinal Cord Injury Unit and the Surgical Intensive Care Unit, both of which utilised primary care nursing, and one neurosurgical ward where nursing care was provided on a 'functional' or task oriented basis. Twelve of the 17 cases were studied between June and August 1984. The 5 remaining cases were studied between October 1984 and March 1985.

\section{Methods}

The impact of continuous turning on direct care time was assessed in patients with acute SCI who were randomly assigned to continuous or intermittent turning. Patients randomised to intermittent turning were treated on regular hospital beds, while patients randomised to continuous turning were treated on Mark II or Mark III automatic turning beds, supplied by Kinetic Concepts Incorporated. Stryker frames were not used. A time-keeping method was devised to measure activities requiring patient contact including nursing observations, and nursing treatments, such as turning, skin care, feeding, hygiene, and transfers from bed to chair. These activities correspond closely with activities defined as 'direct nursing care' by other investigators (Thompson and Wilson, 1981).

Previous studies included only direct care provided by the nursing staff (Thompson and Wilson, 1981; Tilquin, 1981; Adelstein and Watson, 1983). However, because of the team approach to the care of patients with acute SCI, many other health care professionals such as physiotherapists and occupational therapists perform significant roles in bedside patient care. The impact of the care provided by other staff members on direct nursing care time, and the impact of the method of turning on the care time provided by these other workers are not known. Therefore, in the present study, patient contact activities performed by all those providing care. were also included in the timing assessments.

\section{Subjects}

Patients with acute SCI identified in the emergency department by neurosurgical housestaff were entered into the study within 24 hours of admission. Following informed consent, patients were randomly assigned to continuous or intermittent 
turning treatments. Timing usually commenced within 1 to 3 days of admission, although, in some cases, timing was delayed due to the unavailability of a trained observer.

\section{Timing procedure}

A standardised time-keeping form for recording time spent by hospital staff in patient contact activities was designed and tested. This form was derived from the PRN system which provides a measurement of nursing care required (Tiliquin, 1981). Items relevant to SCI, and not included in the PRN system, such as the application of a Halo Vest, were added. The 20 activity categories included in the timekeeping form are shown in Table I. Only those activities involving patient contact such as nurses' contacts with patients, both on and off the ward, were timed, excluding nursing care in the operating or recovery rooms.

As noted above, the activities of non-nursing hospital staff involved in patient contact activities at the bedside were also timed. Fourteen categories of staff were identified on the form by code letters. Registered nurses, comprising $90 \%$ of the nursing staff, and registered nursing assistants comprising the remaining $10 \%$ were considered in the same group. The staff who were timed, included the following: nurse, physician, halo team, genito-urinary technician, physiotherapist, occupational therapist, speech pathologist, psychologist, nutritionist, social worker, orderly, chaplain, and a volunteer. Housekeeping and dietary staff were the only categories of hospital employees with patient contact who were not included.

The staff involved in each patient contact activity were indicated in the timekeeping form, and the time for each activity was multiplied by the number of staff present. For example, log rolling and positioning of a patient requiring 3

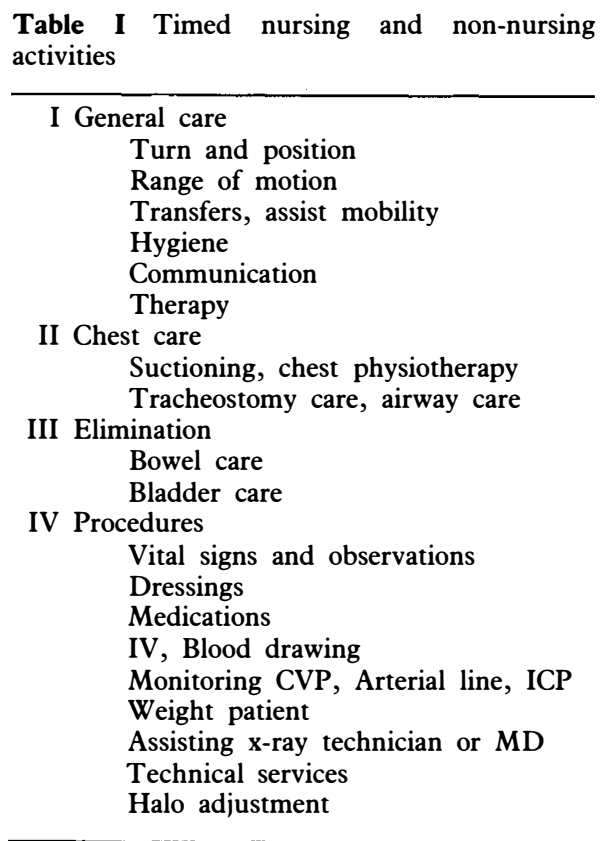


nurses working for 5 minutes was recorded in the time keeping form as $3 \mathrm{~N}$ for 5 minutes or 15 minutes of direct nursing care.

The timing was performed by 5 trained observers who were trained in timing techniques during a 2 week period. Three were nursing students who had completed 1 year of education at a college of nursing, one was a nursing research assistant, and the remaining one was one of the authors (J.B.). Inter-observer reliability for the 5 observers was assessed prior to the commencement of the study period.

Observers were provided with stop watches and timekeeping forms and positioned away from the bedside, but in view of the assigned patients. Each patient staff interaction was timed to the nearest 5 seconds. Placement of the observers away from the bedside allowed timing of patient contact activities without interference with the staff or patients. For example, in the open area of the intensive care unit, the observer was positioned beside the nursing desk. When a curtain was pulled around a patient to allow privacy for an activity, the observer continued timing of the individual at the bedside. In this manner, both patients and staff had privacy assured. However, because patients could not be seen at all times, the exact time taken for each activity performed behind a drawn curtain could not be determined, and therefore, in these instances, the total time for a group of activities was recorded, (e.g. monitoring vital signs and dressing change).

Patients were timed for 8 hour periods corresponding to 8 hour nursing shifts. Each patient was timed during the day shift (07.30-15.30 hours), and when observers were available, patients were also timed during the evening (15.30-23.30 hours) and night (23.30-07.30 hours) shifts. Attempts were made to time the day shifts during the initial 2 weeks of each patient's care to allow comparison of patients treated under similar clinical circumstances. Evening and night shift observations were made when the trained observers were not required for day shift timing activities. All timing was performed on the basis of one trained observer per shift per patient, with meal and rest breaks provided by one of the authors, or by the nursing research assistant.

\section{Data analysis}

Mean direct nursing time per 8 hour shift was determined for each patient. The direct total staff care time, which included the patient contact activities of all hospital personnel, including nurses, was also calculated for each patient. t-Tests were used to test the hypothesis that SCI patients managed with continuous turning required less direct nursing and direct total staff care time when managed with intermittent turning.

Mean direct care times provided by individual categories of hospital staff were also calculated to allow determination of the relative amount of time contributed by each group to the care of patients with acute SCI.

\section{Results}

\section{Subjects}

During the 10 month study period, 15 patients with acute SCI admitted within 24 
hours of injury were included in the study. Two additional patients were included who were transferred to the Acute Spinal Cord Injury Unit from other acute care centres more than 24 hours following injury. Definitive management of their spinal injuries had not occurred prior to admission, and therefore their investigation and management proceeded as for the other 15 patients. Sixteen of the 17 patients were male.

Of the 17 patients, 9 were treated with continuous turning and 8 with intermittent turning (Table IIA and IIB). In the continuous turning group, 6 patients had cervical injuries and 3 had thoracic or lumbar injuries. Three of the cervical injuries had complete SCI, 1 had an incomplete injury with sparing of sensation below the level of injury, and the other 2 presented with a Brown Séquard syndrome. Two of the patients with thoracic or lumbar injuries had

Table IIA Continuous turning group: age, injury level, spinal cord injury scale, presence of multiple trauma and direct care time per 8 hour day shift in the initial two weeks in hospital

\begin{tabular}{|c|c|c|c|c|c|c|c|}
\hline $\begin{array}{l}\text { Patient } \\
\text { No. }\end{array}$ & Age & Level & $\mathrm{SCIS}^{\star}$ & $\begin{array}{l}\text { Multiple } \\
\text { trauma }\end{array}$ & $\begin{array}{l}\text { No of days } \\
\text { timed in } \\
\text { initial } \\
2 \text { weeks }\end{array}$ & $\begin{array}{l}\text { Direct nursing } \\
\text { care time } \\
\text { (minutes } \pm S D)\end{array}$ & $\begin{array}{c}\text { Direct staff } \\
\text { care time } \\
\text { (minutes } \pm \mathrm{SD})\end{array}$ \\
\hline 1 & 67 & $\mathrm{C} 1 / 2$ & 7 & - & 1 & $121 \pm 0$ & $192 \pm 0$ \\
\hline 2 & 28 & C $3 / 4$ & 1 & - & 2 & $141 \pm 10$ & $247 \pm 3$ \\
\hline 3 & 23 & C 4 & 1 & - & 5 & $141 \pm 34$ & $287 \pm 76$ \\
\hline 4 & 13 & C 4 & 1 & - & 10 & $125 \pm 29$ & $270 \pm 52$ \\
\hline 5 & 50 & C 5/6 & 2 & - & 0 & & $230 \pm 69$ \\
\hline 6 & 18 & C 6 & 7 & - & 10 & $140 \pm 72$ & \\
\hline 7 & 18 & T 3 & 1 & - & 2 & $93 \pm 24$ & $156 \pm 34$ \\
\hline 8 & 36 & $\mathrm{~T} 4$ & 1 & + & 10 & $166 \pm 54$ & $259 \pm 64$ \\
\hline 9 & 42 & T $5 / 6$ & 2 & + & 6 & $111 \pm 16$ & $297 \pm 140$ \\
\hline Mean & $33 \pm 17$ & & $2 \cdot 5 \pm 2 \cdot 5$ & & $6 \pm 4$ & $130 \pm 22$ & $242 \pm 48$ \\
\hline
\end{tabular}

^SCIS-Spinal Cord Injury Scale, Tator 1983.

Gradel = complete cord injury, grades $2-9=$ varying degrees of incomplete injury, and grade $10=$ normal.

Table IIB Intermittent turning group: age, injury level, spinal cord injury scale, presence of multiple trauma and direct care time per 8 hour day shift in the initial two weeks in hospital

\begin{tabular}{lccccccc}
\hline Patient & Age & Level & SCIS & $\begin{array}{c}\text { Multiple } \\
\text { trauma }\end{array}$ & $\begin{array}{c}\text { No of days } \\
\text { timed in } \\
\text { initial } \\
\text { 2 weeks }\end{array}$ & $\begin{array}{c}\text { Direct nursing } \\
\text { care time } \\
\text { (minutes } \pm \text { SD) }\end{array}$ & $\begin{array}{c}\text { Direct staff } \\
\text { care time } \\
\text { (minutes } \pm \text { SD) }\end{array}$ \\
\hline 10 & 48 & C 4/5 & 7 & + & 10 & $101 \pm 46$ & $165 \pm 66$ \\
11 & 28 & C 5 & 1 & - & 10 & $198 \pm 72$ & $344 \pm 145$ \\
12 & 30 & C 5/6 & 7 & - & 3 & $105 \pm 17$ & $187 \pm 6$ \\
13 & 45 & C 6/7 & 4 & - & 10 & $149 \pm 33$ & $241 \pm 59$ \\
14 & 20 & T 6/8 & 1 & - & 7 & $92 \pm 28$ & $164 \pm 46$ \\
15 & 31 & T 11 & 4 & + & 6 & $112 \pm 51$ & $206 \pm 59$ \\
16 & 17 & T 12 & 1 & - & 9 & $87 \pm 60$ & $154 \pm 79$ \\
17 & 25 & L 2 & 4 & - & 7 & $72 \pm 31$ & $132 \pm 33$ \\
Mean & $31 \pm 11$ & & $3.6 \pm 2.5$ & & $8 \pm 2$ & $115 \pm 41$ & $199 \pm 67$ \\
\hline
\end{tabular}

$\star$ SCIS_Spinal Cord Injury Scale, Tator 1983.

Grade $1=$ complete cord injury, grades $2-9=$ varying degrees of incomplete injury, and grade $10=$ normal. 
complete SCI, and the third had some preservation of sensation below the level of injury. In the intermittent turning group, there were 4 cervical cord injuries and 4 thoracic or lumbar injuries. Of the cervical injuries, one had a complete cord injury, one had significant preservation of dorsal column sensation but no motor function below the level of the lesion, and two presented with incomplete motor and sensory deficits. Table IIA and IIB summarise the age, injury level, admission neurological status based on the previously described Spinal Cord Injury Scale (Tator, 1983) and the treatment given. Injuries other than the SCI were classified according to the Abbreviated Injury Scale, and those patients with additional injuries of grade three severity or higher were classified as multiple trauma (Baker et al., 1974; Mayer, Walker and Clark, 1984).

\section{Number of timed shifts}

In 12 patients timing was performed for 5 to 10 day shifts $(07.30-15.30$ hours) during the initial 14 day period following acute SCI. In 4 of the remaining 5 cases, insufficient observers limited the number of timed day shifts to 1 to 3 during the initial 2 weeks of hospitalisation, and in the fifth case, because of insufficient observers, the patient was observed for 8 day shifts during the third and fourth weeks following injury. Five of the 12 patients timed during the initial 2 weeks post-injury were also timed during the third, fourth, or fifth weeks post-injury. In addition, seven of the patients were observed during evening (15.30-23.30 hours) and/or night ( $23.30-07.30$ hours) shifts. In total the 17 patients were timed during 146 day shifts, 7 evening shifts, and 15 night shifts. The 9 continuous turning patients were timed during 70 shifts and the 8 intermittent turning patients were timed during 98 shifts.

\section{Inter-observer reliability of timing technique}

Inter-observer reliability was determined prior to commencement of the study, and repeated assessments of reliability were performed at intervals throughout the study using analysis of variance as described by Winer, 1971. The unbiased reliability coefficient of direct care time measured prior to the commencement of

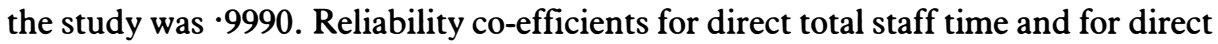
nursing time measured on 8 subjects at intervals throughout the study were 9902 and 9794 respectively. Thus, repeated assessments confirmed continuing reliability of the timing technique.

\section{Comparison of care time for continuous and intermittent turning}

Mean direct nursing care and direct total staff care per day shift during the initial 2 weeks in hospital were determined for each patient (Table IIA and IIB). All mean timing results are expressed as mean $\pm 1 \mathrm{SD}$. The mean direct nursing care time per day shift was $130 \pm 22$ minutes for the 9 patients managed with continuous turning, and $115 \pm 41$ minutes for 8 patients managed with intermittent turning (Table III). The mean care times were not statistically different $(p>\cdot 3$. Direct total staff care time and direct physiotherapy care time were also not significantly different for the two groups (Table IV) $(\mathrm{p}>\cdot 26)$. 
Table III Mean day shift direct care time (minutes) in the initial two weeks for patients with acute spinal cord injury treated with continuous or intermittent turning

\begin{tabular}{lccc}
\hline & $\begin{array}{c}\text { Continuous turning } \\
9 \text { patients, 44 shifts } \\
\text { Minutes } \\
\text { (mean } \pm \text { SD) }\end{array}$ & $\begin{array}{c}\text { Intermittent turning } \\
8 \text { patients, 62 shifts } \\
\text { Minutes } \\
\text { Staff }\end{array}$ & $\begin{array}{c}\text { Minimum } \\
\text { effect size }\end{array}$ \\
\hline Direct nursing care & $130 \pm 22$ & $115 \pm 41$ & 63 \\
Direct physiotherapy care & $33 \pm 13$ & $29 \pm 15$ & 21 \\
Direct total staff care & $261 \pm 23$ & $206 \pm 70$ & 78
\end{tabular}

^Effect size: The study had an $80 \%$ likelihood of detecting a significant difference in a comparison when the mean population difference was in excess of the effect sizes listed (Cohen, 1977).

Table IV Direct nursing care time (minutes) in the initial two weeks following injury for patients with comparable levels and severity of injury managed with continuous and intermittent turning

\begin{tabular}{lcccc}
\hline $\begin{array}{l}\text { Injury level } \\
\text { and severity }\end{array}$ & $\begin{array}{c}\text { No. of } \\
\text { patients }\end{array}$ & $\begin{array}{c}\text { Continuous } \\
\text { turning time } \\
\text { (minutes) }\end{array}$ & $\begin{array}{c}\text { No. of } \\
\text { patients }\end{array}$ & $\begin{array}{c}\text { Intermittent } \\
\text { turning time } \\
\text { (minutes) }\end{array}$ \\
\hline Cervical complete & 3 & $136 \pm 9$ & 1 & $198 \pm 72$ \\
Cervical incomplete & 2 & $130 \pm 13$ & 3 & $118 \pm 27$ \\
Thoracic complete & 1 & $93 \pm 24$ & 2 & $90 \pm 4$ \\
Thoracic incomplete & 1 & $111 \pm 16$ & 2 & $92 \pm 28$
\end{tabular}

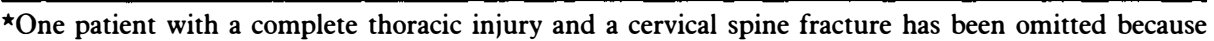
of lack of an injury of similar severity in the intermittent turning group.

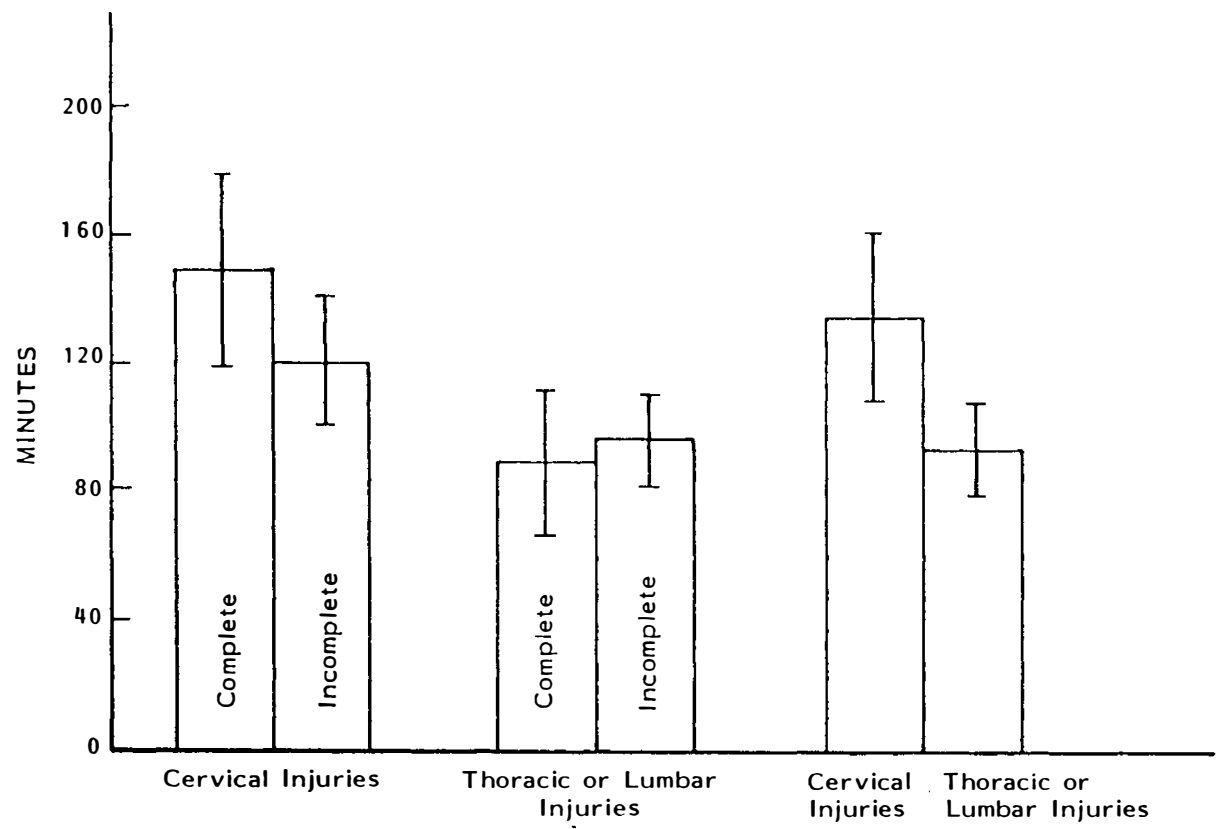

Figure 1 Direct nursing care time in minutes (mean \pm SD) for patients grouped by level and severity of injury. Patients with cervical injuries required significantly more nursing care time than patients with thoracic or lumbar injuries $(\mathrm{P}=\cdot 04)$. 


\section{Effect of level and severity of injury on care time}

Patients with similar degrees of neurologic deficit managed with continuous or intermittent turning were grouped by neurologic level and compared (Fig. 1). Direct nursing care time was significantly greater for patients with cervical injuries managed with either turning method (136 \pm 27 minutes) than for patients with thoracic or lumbar injuries alone $(95 \pm 15)(p<\cdot 04)$. However, there were several exceptions. Two patients with central cord syndrome and significant preservation of motor and sensory function required much less care. Both patients were in the intermittent turning group, and their mean direct time was 103 minutes which was $25 \%$ less than for other patients with cervical injuries. One patient with paraplegia due to a thoracic injury also had a cervical spine injury which did not produce a neurologic deficit. This patient had a mean direct nursing care time of 166 minutes which approximated the mean care time for patients in the cervical injury group. Direct nursing care times for patients with similar levels of injury and severity of injury in the two treatment groups are compared in Table IV.

\section{Effect of complications and procedures on care time}

As expected, some patients had significant day-to-day variations in both direct staff care and direct nursing care times. For example, patient no. 11 had a cervical cord injury and was timed for 10 shifts during the initial 2 weeks following SCI. The largest daily values for both direct total staff care and direct nursing care times were associated with severe medical complications such as respiratory failure on day 2 (544 minutes and 329 minutes for staff and nursing care respectively), and atelectasis and respiratory arrest on day 12 (634 minutes and 248 minutes respectively) (Table $\mathrm{V}$ ). In other patients, day to day variations were less extreme, but when direct care time for individual patients exceeded the mean by more than one standard deviation, the increased time was usually associated with medical complications or radiologic investigations (Table VI).

\section{Effect of interval from trauma on care time}

There was a trend towards decreasing direct nursing care time with increasing number of days following injury as shown by the 4 thoracic and lumbar injuries

Table $\mathbf{V}$ Day shift care time for patient no. 11 with a cervical injury

\begin{tabular}{lccc}
\hline Day post-injury & $\begin{array}{c}\text { Direct total } \\
\text { staff time } \\
\text { (minutes) }\end{array}$ & $\begin{array}{c}\text { Direct } \\
\text { nursing time } \\
\text { (minutes) }\end{array}$ & $\begin{array}{c}\text { Medical } \\
\text { complications }\end{array}$ \\
1 & 180 & 130 & - \\
2 & 544 & 329 & Respiratory failure \\
3 & 378 & 201 & - \\
4 & 213 & 117 & - \\
5 & 344 & 157 & - \\
8 & 294 & 162 & - \\
9 & 324 & 225 & - \\
10 & 225 & 135 & Atelectasis, respiratory arrest \\
11 & 300 & 193 & 248 \\
12 & 634 & & - \\
\hline
\end{tabular}


who were followed for more than 2 weeks (Table VII). Because of low patient numbers, statistical analysis of this inverse relationship was not performed. In the 4 cases presented, the direct nursing care time for medically stable patients just prior to their transfer to a rehabilitation hospital was less than half the care time during the initial week following injury.

\section{Effect of shift on care time}

Of the 7 patients who were also timed during the evening (15.30-23.30 hours)

Table VI Analysis of shifts in which direct care time was equal to or greater than one SD above the mean care time

\begin{tabular}{|c|c|c|c|c|c|}
\hline $\begin{array}{l}\text { Patient } \\
\text { No. }\end{array}$ & $\begin{array}{l}\text { No. of } \\
\text { shifts }\end{array}$ & $\begin{array}{l}\text { No. of } \\
\text { hifts wit } \\
\text { staff } \\
\text { re } \pm 1 \mathrm{~S} \\
\text { above } \\
\text { mean }\end{array}$ & $\begin{array}{l}\text { Events on } \\
\text { index days }\end{array}$ & $\begin{array}{l}\text { With } \\
\text { nursing } \\
\text { care } \\
\pm 1 \text { SD } \\
\text { above } \\
\text { mean }\end{array}$ & $\begin{array}{l}\text { Events on } \\
\text { index days }\end{array}$ \\
\hline 3 & 5 & 1 & SEP & 1 & IVP preparation \\
\hline 4 & 10 & 1 & SEP & 2 & $\begin{array}{l}\text { Urinary tract infection } \\
\text { with systemic symptoms }\end{array}$ \\
\hline 5 & 7 & 2 & - & 1 & IVP preparation \\
\hline 6 & 10 & 3 & $\begin{array}{l}\text { (1) Tomograms (attended) } \\
\text { (2) Applying Halo vest } \\
\text { (3) Investigation of chest pain }\end{array}$ & 1 & Tomograms (attended) \\
\hline 8 & 14 & 0 & - & 1 & Investigation of chest pain \\
\hline 9 & 5 & 2 & $\begin{array}{l}\text { (1) IVP preparation } \\
\text { (2) SEP }\end{array}$ & 1 & IVP preparation \\
\hline 10 & 10 & 1 & Initial day in hospital & 1 & Initial day in hospital \\
\hline 11 & 10 & 2 & $\begin{array}{l}\text { (1) Respiratory failure } \\
\text { (2) Respiratory arrest }\end{array}$ & 2 & $\begin{array}{l}\text { (1) Respiratory failure } \\
\text { (2) Respiratory arrest }\end{array}$ \\
\hline 13 & 12 & 2 & $\begin{array}{l}\text { (1) SEP } \\
\text { (2) Orientation new nurse }\end{array}$ & 2 & $\begin{array}{l}\text { (1) Redislocation } \\
\text { (2) Orientation new nurse }\end{array}$ \\
\hline 14 & 18 & 0 & - & 0 & - \\
\hline 15 & 9 & 1 & $\begin{array}{l}\text { CT and tomograms } \\
\text { (attended) }\end{array}$ & 1 & $\begin{array}{l}\text { CT and tomograms } \\
\text { (attended) }\end{array}$ \\
\hline 16 & 9 & 2 & (1) Chest pain & 1 & DVT \\
\hline 17 & 18 & 1 & Draining surgical site & 0 & - \\
\hline
\end{tabular}

SEP $=$ Somatosensory evoked potential studies performed.

Table VII Mean direct nursing care time per day shift (minutes) for four patients timed for more than 2 weeks after admission

\begin{tabular}{|c|c|c|c|c|c|}
\hline \multirow[t]{3}{*}{$\begin{array}{l}\text { Patient } \\
\text { no. }\end{array}$} & \multicolumn{5}{|c|}{ Time in minutes (mean $\pm S D$ ) and no. of shifts } \\
\hline & \multicolumn{5}{|c|}{ Week post-injury } \\
\hline & 1 & 2 & 3 & 4 & 5 \\
\hline 8 & $157 \underset{(5)}{ \pm} 60$ & $\begin{array}{c}156 \pm 46 \\
(4)\end{array}$ & $205 \pm 1$ & - & $56 \pm 9$ \\
\hline 14 & $120 \pm 5$ & $74 \pm 19$ & $58 \pm 21$ & $31 \underset{(3)}{ \pm} 18$ & $40 \pm 7$ \\
\hline 15 & $134 \pm 21$ & $92 \pm 68$ & $45 \pm 13$ & - & - \\
\hline 17 & $70 \pm 18$ & $73 \pm 37$ & $55 \pm 20$ & $52 \pm 6$ & $31 \pm 6$ \\
\hline
\end{tabular}


and/or night (23.30-07.30 hours) shifts, in all but one (patient no. 4), the evening and night shift timing occurred when the patients were medically stable and just prior to their transfer to a rehabilitation hospital. Mean evening and night shift direct nursing care times for these 7 patients were $27 \pm 12$ minutes and $34 \pm 24$ minutes respectively (Table VIII). In general, the evening and night shift care times for medically stable patients were only 10 to $30 \%$ of the day shift times determined in the same 24 hour interval (Fig. 2).

Table VIII Comparison of direct nursing care time and staff care time for day, evening and night shifts in 7 patients $(\mathrm{N}=$ no. of shifts)

\begin{tabular}{|c|c|c|c|c|c|c|c|c|c|c|}
\hline \multirow{2}{*}{$\begin{array}{l}\text { Patient } \\
\text { no. }\end{array}$} & \multirow{2}{*}{$\begin{array}{l}\text { Week } \\
\text { post- } \\
\text { injury }\end{array}$} & \multirow[b]{2}{*}{ Day } & \multicolumn{4}{|c|}{$\begin{array}{c}\text { Direct } \\
\text { nursing care time (minutes) }\end{array}$} & \multirow[b]{2}{*}{$\mathrm{N}$} & \multicolumn{3}{|c|}{$\begin{array}{c}\text { Direct } \\
\text { staff care time (minutes) }\end{array}$} \\
\hline & & & $\mathrm{N}$ & Evening & $\mathrm{N}$ & Night & & Day & Evening & Night \\
\hline 17 & 5 & 3 & 4 & 11 & 1 & 1 & 1 & $87 \pm 26$ & 25 & 23 \\
\hline 14 & 5 & $41 \pm 8$ & 3 & - & - & $8 \pm 2$ & 2 & $96 \pm 28$ & - & $28 \pm 4$ \\
\hline 10 & 2 & $75 \pm 26$ & 3 & $29 \pm 4$ & 2 & - & - & $135 \pm 71$ & $39 \pm 11$ & - \\
\hline 5 & 5 & $130 \pm 24$ & 3 & $40 \pm 11$ & 2 & - & 2 & $135 \pm 71$ & $91 \pm 16$ & $25 \pm 2$ \\
\hline 8 & 3 & $195 \pm 18$ & 3 & - & - & $63 \pm 4$ & 2 & $373 \pm 58$ & - & $81 \pm 4$ \\
\hline 4 & 2 & $105 \pm 47$ & 5 & $27 \pm 17$ & 3 & $56 \pm 42$ & 5 & $274 \pm 58$ & $65 \pm 1$ & $73 \pm 39$ \\
\hline & 2 & $105 \pm 17$ & 3 & - & - & $39 \pm 8$ & 2 & $186 \pm 6$ & - & $53 \pm 8$ \\
\hline time/shift & & $98 \pm 55$ & & $27 \pm 12$ & & $32 \pm 24$ & & $200 \pm 105$ & $55 \pm 105$ & $47 \pm 26$ \\
\hline
\end{tabular}

^Shifts timed for direct staff care time were identical to the shifts timed for nursing care.

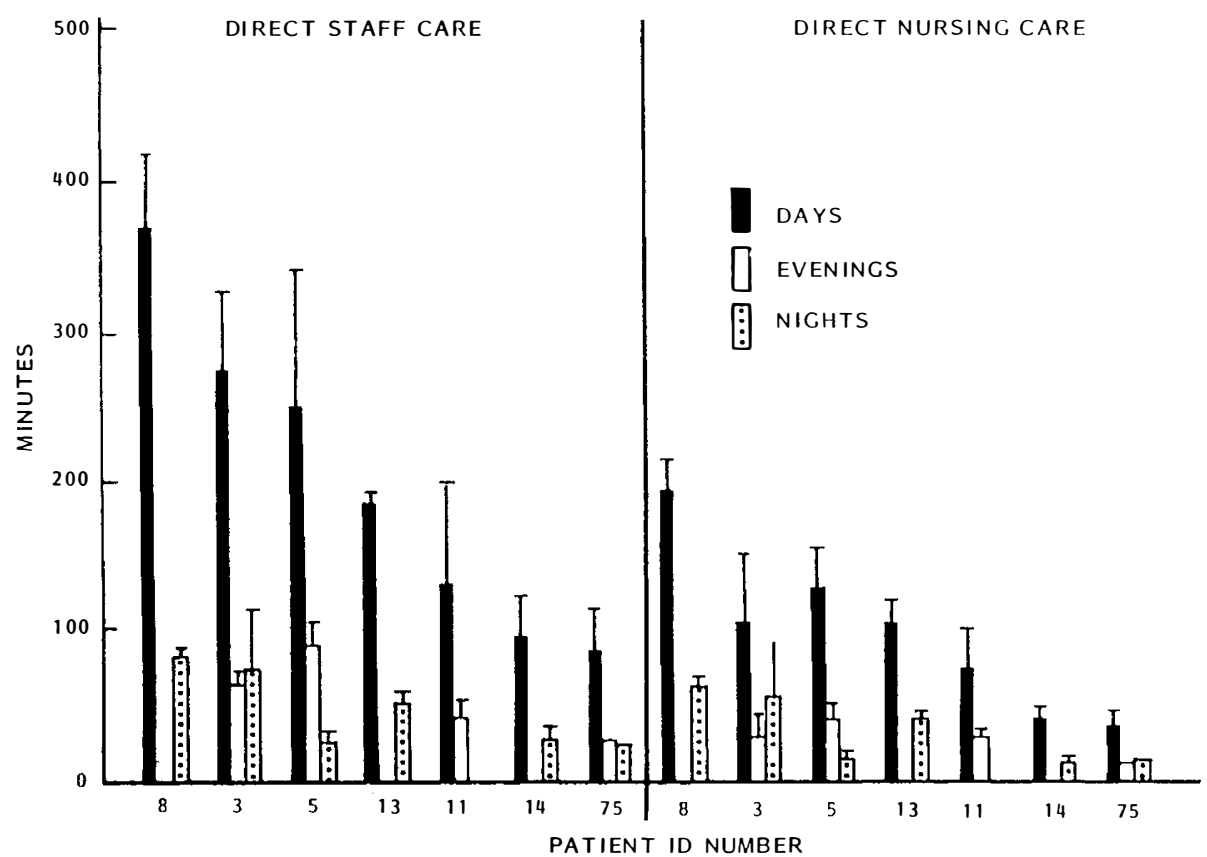

Figure 2 Direct care time in minutes (mean \pm SD) during the day, evening, and night shifts for 7 patients with acute spinal cord injury. 


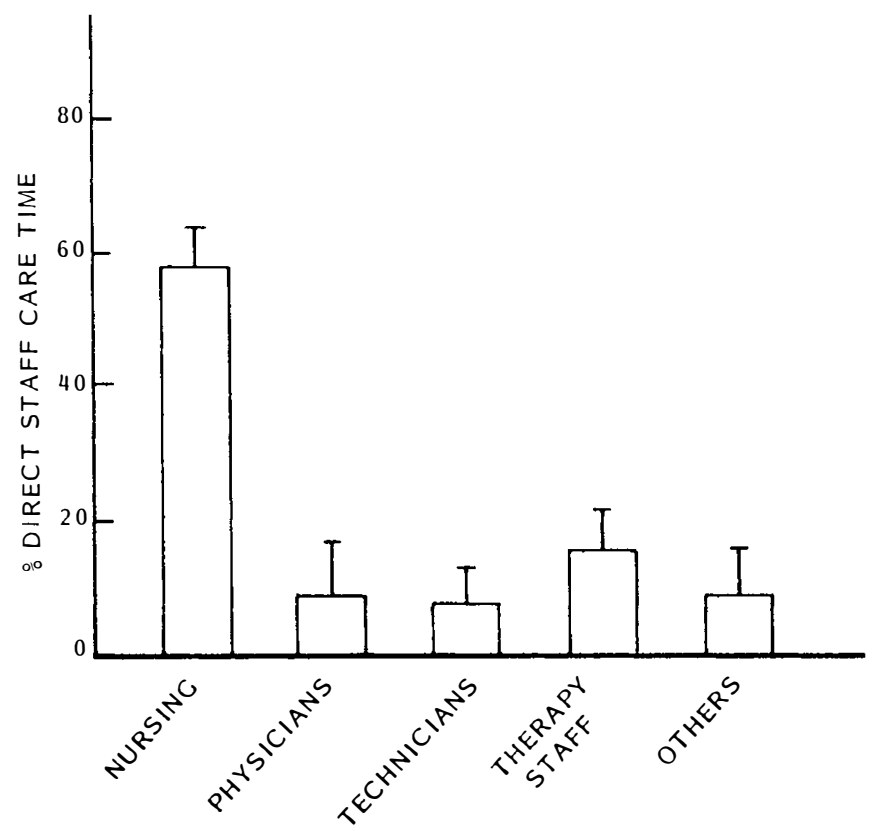

Figure 3 Per cent of direct staff care time contributed by different categories of hospital staff per 8 hour day shift per patient during the initial weeks following injury.

\section{Proportion of care delivered by nursing versus non-nursing staff}

Nursing staff provided, on average, $55 \%$ of the direct patient care time. Other hospital staff including physiotherapists, occupational therapists, physicians, technicians and nurses specialising in care of Halo equipment, provided lesser proportions of the direct care (Fig. 3). Social services, orderlies, chaplains, nutritionists, and the intravenous team together also contributed significantly to clinical care time.

\section{Discussion}

Automated, mechanical, continuous turning has been shown to be an excellent alternative to manual intermittent turning of patients with acute SCI (Green, 1980). Indeed, some studies have reported that spinal alignment is better maintained, medical complications are reduced, and nursing care time is decreased with continuous turning treatment (Keane, 1977; Green, 1983; Adelstein, 1983).

Although the average direct nursing care time for patients with acute SCI has not been reported previously, some relevant timing data is available. For example, in a combined neurological and neurosurgical ward Thompson and Wilson (1981) found that direct nursing care time for a registered nurse averaged 149 minutes per day shift which is similar to the mean direct nursing care time of $136 \pm 27$ minutes in the present study.

Several critical assumptions and qualifications were made in the present study. For example, only day shift times were used for the comparisons between continuous and intermittent turning because pilot data demonstrated that the 
majority of care time occurred during the day shift, and this proved to be true during the study (Fig. 3). This study examined only direct patient contact time and omitted the nursing time for non-contact care activities. In addition, no attempt was made to measure the quality of care, and thus, the results do not necessarily represent the optimal care time for patients with acute SCI.

The present study failed to demonstrate a reduction in direct nursing care time or direct total staff care time for patients managed with continuous turning. The discrepancy between our results and those of Adelstein and Watson (1983) who reported a reduction may be related to a number of factors including variation in the activities which were assessed in the two studies, differences between the 2 patient groups in the present study, and the much larger number of cases which would have been required to show a difference in view of the wide variations in individual care times in this study (see effect sizes, Table IV). Unfortunately, during the portion of the study in which observers were available for timing patients, more patients with severe cord injury were allocated to the continuous turning group. For example, the continuous turning group had 5 of 9 patients with complete cord injury whereas the intermittent group had only 3 of 8 with complete cord injury. Also, 6 of 9 in the continuous group were cervical injuries, whereas only 4 of 8 in the intermittent group were cervical injuries. The importance of these factors was recognised when patient care time was considered for patients grouped by severity and level of injury rather than by treatment group (Fig. 1). The third factor to be considered was the presence of day to day variations of 30 to 60 minutes in the direct nursing care time for each patient. Retrospective analysis of the data suggested that the presence of medical complications and the performance of investigative procedures were two important causes of this variation. The trend of decreasing care time with increasing interval from injury, another identified source of variation, was addressed by attempting to time each patient during the initial 2 weeks following injury.

In addition to direct nursing care, each patient received an average of 110 minutes of direct care time from other categories of health care providers. Care time delivered by non-nursing staff was similar for the two treatment groups, and therefore did not affect the comparison of the two turning methods. However, it is important to recognise the significant contribution of other health care professionals and the rehabilitation team to bedside patient care times.

Although patient care time did not differ between the two treatment groups, some major advantages of continuous turning treatment were observed. Spinal alignment was easier to maintain during continuous turning in patients with injuries of the cervical spine. Continuous turning allowed radiological procedures on the spine, chest and abdomen to be more easily performed without having to alter the patients' position in bed. Therapy and nursing staff indicated that the continuous turning bed facilitated patient positioning for such activities as chest physiotherapy. With continuous turning, one nurse was sufficient to provide care for an individual SCI patient without having to rely on the assistance of other nurses on the ward for patient turning every two hours.

\section{Conclusions}

Because nurses' salaries form 30 to $60 \%$ of hospital operating budgets, factors 
effective in reducing nursing care time could have a significant impact on health care costs. The present study tested the hypothesis that continuous turning was effective in reducing direct nursing care time. Although no reduction in nursing time was detected with this method, the power of the study was low. Numerous variables including the vertebral level of injury, severity of cord injury, interval from injury, medical complications and investigative procedures appeared to contribute to the wide variations in care time and the resulting inability to detect treatment differences. Successful future research on time saving management strategies for health care delivery in the field of SCI must take into account these variables.

\section{Acknowledgements}

The authors wish to acknowledge the assistance of V. Edmonds RN, K. Weaver RN, and of the three nursing students who performed the timing, J. Delmage, M. Johnston, and E. Stewart. We thank the medical and nursing staff of Sunnybrook Medical Centre for their support of this research. J. Bugaresti MD was supported by a Fellowship from the Alberta Heritage Foundation for Medical Research. C. H. Tator was Head of the Acute Spinal Cord Injury Unit at Sunnybrook Medical Centre during the course of this study. The Kinetic Treatment Tables and other funds for this research were generously donated by Kinetic Concepts Inc.

\section{References}

Adelstein W, Watson P 1983 Cervical spine injuries. Fournal of Neurosurgical Nursing 15:65-71.

BAKER S et al. 1974 The injury severity score: A method for describing patients with multiple injuries and evaluating emergency care. The fournal of Trauma 14:187-?.

BRACKET TO, GORDON N 1984 Comparison of the wedge turning frame and kinetic treatment table in the acute care of spinal cord injury patients. Surgical Neurology 22:53-66.

COHEN J 1977 Statistical power analysis for the behavioral sciences revised ed. Academic Press, New York.

GreEN BA, GreEn KL, Klose KJ. 1983 Kinetic therapy for spinal cord injury. Spine 8:722-727.

KeANE FX 1970 Roto-rest. Paraplegia 7:254-258.

KEANE FX 1977 Pain and cervical traction variation during manual turning. Paraplegia 15:343-348.

MAYER T, WALKER M, CLARK P 1984 Further experience with the modified abbreviated injury severity scale. Fournal of Trauma 24,(1)31-34.

STODDART GL, VERRIER MC 1980 Economic implications of rehabilitation options for patients with quadriplegia. Clinical and Investigative Medicine 3:245-25 2.

TATOR CH 1983 Sunnybrook Cord Injury Scales for assessing neurological injury and neurological recovery. In: Early Management of Acute Spinal Cord Injury, Ch 2, 7-24, Raven Press, New York 7-24.

Thompson A, WILSON A 1981 Quantity first, then quality. The Canadian Nurse 22-26.

TILQUIN C 1981 PRN 80: The Measurement of the level of nursing care required. University of Montreal.

WINER BM 1971 Statistical Principles in Experimental Design. (2nd ed) McGraw Hill Book Company, New York. 